\title{
DAS RECENTES CRISES FINANCEIRAS À CRISE PANDÉMICA QUAL O VALOR DO TRABALHO?
}

\section{FROM RECENT FINANCIAL CRISES TO THE PANDEMIC CRISIS WHAT IS THE VALUE OF WORK?}

\author{
Andreia Santos \\ Centro de Estudos Sociais da Universidade de Coimbra, Faculdade de Economia, Universidade de Coimbra. \\ Colégio de S. Jerónimo, Largo D. Dinis, Apartado 3087, 3000-995 Coimbra, Portugal. \\ E-mail: andreiasantos@ces.uc.pt; andreiasant1@hotmail.com | ORCID: https://orcid.org/0000-0003-2569-6991
}

Resumo: Vivemos tempos estranhos, onde a sociedade e o seu funcionamento se alteraram profundamente. Face a uma crise de saúde pública, todas as esferas da sociedade sofreram pontos de rutura, nas quais o trabalho, inevitavelmente, assume um papel central. Este artigo contempla uma reflexão sobre o contexto de pandemia, mas pretende, principalmente, debater sobre qual o valor do trabalho. Focam-se três pontos essenciais: a centralidade do trabalho e dos seus direitos no funcionamento das sociedades; a sua instrumentalização na regulamentação económica, política e social patente nas reformas levadas a cabo desde os anos 1970; e como velhas e novas questões que permeiam o mundo laboral nos instigam a questionar os caminhos percorridos. O objetivo é que se reconheça no valor do trabalho e seus direitos, a afirmação da dignidade humana e de mecanismos redistributivos e quadros institucionais e legais orientados para a solidariedade e coesão social.

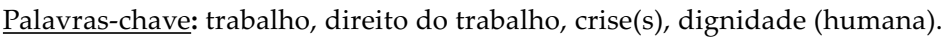

\begin{abstract}
We live in strange times in which the functioning of society has changed profoundly. In face of a public health crisis, all spheres of society have suffered breaking points. Among these, work inevitably takes on a central role. This article reflects about the current pandemic context, but mainly intends to debate about the value of work. Three essential points are put forward: the centrality of work and its rights in the functioning of societies; work's instrumentalization in the economic, political and social regulation made clear throughout the reforms carried out since the 1970s; and how old and new issues attached to the world of work instigate us to question the chosen paths. The goal is to recognize in the value of work and its rights, the affirmation of human dignity and redistributive mechanisms and institutional and legal frameworks based on solidarity and social cohesion.
\end{abstract}

Keywords: work, labour law, crisis(es), human dignity.

\section{Introdução}

Vivemos tempos estranhos, onde a sociedade e o seu funcionamento se alteraram profundamente. Face a uma crise de saúde pública motivada pela pandemia do COVID 19, todas as esferas da vida social foram submersas sobre transformações que conduzem a pontos de rutura, nas quais o trabalho, inevitavelmente, assume um papel central. Sendo um elemento essencial de integração social e peça fundamental 
no desenvolvimento da economia, a impossibilidade de tudo permanecer como dantes, levanta imensas questões, umas novas, mas a maioria, questões recorrentes. Por sua vez, as "questões recorrentes" relacionadas com a precariedade e insegurança laborais, sofrem agora um aprofundamento que permite uma reflexão sob o contexto atual, mas principalmente, sobre o valor do trabalho. Este é um artigo que contempla a situação de pandemia que assola a Europa e o mundo, porém, não é um artigo sobre esta temática, é sim, sobre a importância do trabalho e dos seus direitos enquanto base para sociedades mais justas e democráticas.

Ancorado na área da sociologia, mais especificamente, da sociologia do trabalho, do direito e da política, e numa análise quantitativa de dados estatísticos de diferentes fontes, este artigo estrutura-se em três pontos essenciais. Num primeiro momento, estabelece-se a relevância do trabalho e dos seus direitos enquanto elemento central no funcionamento das sociedades. De seguida, demonstra-se como nas recentes crises, nomeadamente, desde a década de 1970, passando pela crise financeira em 2008 e culminando no momento atual de exceção causado pela pandemia, o trabalho tem sido peça fulcral nas soluções encontradas, demonstrando que a sua instrumentalização é decisiva face a escolhas políticas, económicas e sociais. Por último, tendo presente o cenário exposto, identificam-se velhas e novas questões que permeiam o mundo laboral, e nos instigam a questionar os caminhos percorridos.

\section{A centralidade do trabalho e os seus direitos}

O trabalho e os seus direitos desempenham um papel fundamental na vida dos indivíduos. Contrariando as teses do seu fim (Méda, 1999; Rifkin, 1995), o trabalho permanece um espaço decisivo de construção identitária, um campo de afirmação de qualificações, uma fonte de emanação de direitos e de cidadania, persistindo como uma dimensão fulcral de sociabilidade que liga o indivíduo à natureza e à sociedade (Estanque \& Costa, 2012). O trabalho é "uma atividade central que estrutura a vida dos indivíduos e a vida social em geral (...) fonte e espaço de dignidade e valorização humana" (Silva, 2007, p. 88).

A tese da centralidade do trabalho sustenta que a atividade trabalho é fundamental para os indivíduos em três sentidos interdependentes. O primeiro, no sentido psicológico, sendo um elemento indispensável na constituição da identidade individual e no desenvolvimento das suas capacidades. O trabalho é central na aprendizagem cognitiva, na maturação emocional e para o desenvolvimento moral do indivíduo. Nesta medida, quando o trabalho não consegue corresponder a estas potencialidades de desenvolvimento e formação de identidade, torna-se num 
elemento disruptor devido ao seu significado psicológico. A este sentido, estão associadas duas dimensões sociais relacionadas entre si. A primeira implica que o domínio geral dos homens sobre as mulheres é estruturado essencialmente pela organização do trabalho. A segunda é a de que o trabalho possui um papel substantivo e irredutível na estrutura e na qualidade das relações sociais e na vida política. As experiências individuais e formas de relação interpessoais moldadas pela organização do trabalho têm um impacto profundo nas relações sociais fora da esfera laboral, influenciando modos de civilidade e estabelecendo vínculos sociais que tanto podem conduzir à cooperação, como pelo contrário, à falta de confiança e efeitos de exclusão. Tal, por sua vez, encontra reflexos no modo como o coletivo se organiza na vida política (Deranty, 2015, p. 105).

Esta perspetiva de que a divisão do trabalho está na raiz da vida social e política é uma visão clássica da sociologia. Karl Marx ${ }^{1}$ com a análise da relação entre capital, trabalho e alienação, Émile Durkheim ${ }^{2}$ e as formas de solidariedade mecânica e solidariedade orgânica com a afirmação da divisão do trabalho social, e Max Weber $^{3}$ com a análise da ética protestante e do trabalho enquanto origem do racionalismo ocidental manifesta no capitalismo, todos tomam o trabalho como elemento motriz fundamental no funcionamento das sociedades. Em comum, tomando a sua contextualização histórica, a relação entre capital e trabalho é fator estruturante da sociedade. Nesta perspetiva, a centralidade do trabalho é inegável seja como atividade indispensável na forma de obter recursos materiais e imateriais necessários para viver em sociedade, seja pela sua expansão a todas as atividades humanas (Freyssenet, 1999, p. 12).

A centralidade do trabalho está, assim, inevitavelmente relacionada com a evolução da sociedade, evidenciando que a organização do trabalho é em si mesma uma questão política (Dejours \& Deranty, 2010, p. 177). O seu forte carácter político que o situa como principal instrumento de ação perante novos quadros político-económicos, combina os "pontos de apoio e de conexão entre a totalidade do capitalismo (produção, consumo e reprodução), as particularidades desses processos em termos histórico-sociais e as singularidades como efeitos combinados entre o controle, a ideologia e as práticas resultantes" (Costa \& Almada, 2018, p. 163). O trabalho é, por isso, um poderoso fator de integração social, estabelecendo posições, direitos e deveres, e distribuindo os indivíduos numa escala social de prestígio. Porém, ao longo dos anos o significado do trabalho tem-se alterado, tornando-se cada vez mais diversificado, sendo hoje investido com grandes expetativas que entram em conflito com os desenvolvimentos organizacionais e a natureza em permanente mutação do mercado de trabalho (Méda \& Vendramin, 2017, p. 6). O trabalho é, ao mesmo tempo, e variando em diferentes graus: um fator de 
produção; a essência da humanidade; e a principal fonte de direitos e de redistribuição económica, o que reflete a intensa complexidade do seu carácter (Méda, 2016). Analisado em diferentes períodos, estas diferentes camadas ou dimensões identificadas no conceito de trabalho, nos dias de hoje, estão perante uma difícil coexistência, sustentando as perceções e experiências quotidianas dos indivíduos (Méda \& Vendramin, 2017, p. 30).

Os tempos recentes, onde os mercados financeiros assumem papel de destaque, demonstram como o fator trabalho reduz-se às condições de precariedade nas quais o indivíduo desempenha o seu trabalho. A este propósito, Estanque e Costa (2012, p. 173) assinalam que é importante reconhecer que

a retirada de condições de segurança e estabilidade nas relações laborais só pode ter como consequência o esgaçar do próprio tecido social com todo o rol de riscos que isso comporta, tanto para a atividade económica como para a vida das pessoas.

O trabalho é isto mesmo, uma extensão a todas as esferas do indivíduo por se constituir num pilar fundamental da cidadania. Atualmente, o debate sobre o futuro do trabalho assenta, sobretudo, na avaliação dos impactos da inovação tecnológica nas relações laborais, ao que acrescem os impactos das alterações demográficas e ambientais (OIT, 2019). Num futuro onde se prevê a destruição do emprego e desvalorização do trabalhador, e desafios crescentes à regulamentação do trabalho e dos seus direitos (Countoris, 2019; Teles \& Caldas, 2019), é importante não esquecer que este futuro modela, também, as condições e a qualidade de vida dos indivíduos.

Neste cenário, torna-se urgente o debate sobre o valor atribuído ao trabalho nas sociedades contemporâneas. Como nos diz Carvalho da Silva (2020)

(a) centralidade do trabalho deve estar presente na matriz de desenvolvimento de um país, nas políticas de coesão, nas opções macroeconómicas e seus desenvolvimentos, na aplicação dos avanços científicos e tecnológicos impedindo cenários catastrofistas. O Direito do Trabalho e a ética têm de enquadrar os sistemas de relações laborais, libertando-os da submissão às imposições dos mercados, da "competitividade" e da centralidade da máquina.

A ideia fundamental é a de que o trabalho desempenha uma série de papéis universais na vida dos indivíduos e sociedades atendendo: às suas necessidades materiais, proporcionando autorrealização individual e fazendo a conexão entre o indivíduo e a sociedade (ILO, 2018, p. 6). 


\section{Das recentes crises: o trabalho no centro das reformas}

Se tomarmos em consideração as transformações históricas da relação capitalismo - trabalho após a II Guerra Mundial, o surgimento de noções como sociedade pós-industrial, pós-fordismo, flexibilidade e desregulamentação abriram caminho para a fundamentação das reformas laborais. Os seus efeitos questionaram o modelo tradicional de direito do trabalho assente no "círculo virtuoso da economia", na expansão dos Estados-providência, na cidadania industrial e social e na relação salarial fordista. Revelando uma continuidade e "cumplicidade" entre as transformações sociais, políticas e económicas, as alterações efetivas operadas nas relações laborais, apenas demonstram que a revisão das leis laborais surge, invariavelmente, como primeiro recurso para a resolução de dificuldades económicas e sociais (Fernandes, 2012).

Seguindo esta linha de raciocínio é possível identificar os principais momentos-chave através dos quais a instrumentalização do trabalho se torna reflexo da esfera política, económica e social. Partindo dos Trinta Gloriosos Anos, foi sob a ascensão económica e financeira dos países ocidentais que se estabeleceu o objetivo do pleno emprego. O consenso ideológico entre os maiores partidos políticos baseados em ideias económicas keynesianas, combinadas com uma maior intervenção do Estado em estimular a economia e produtividade, e mantendo o equilíbrio económico, dá origem ao modelo fordista. Trata-se de um período de produção em massa de bens estandardizados em fábricas de grande escala, com leis que suportavam a institucionalização das relações laborais promovendo a estabilidade (Hepple \& Veneziani, 2009, pp. 31-128). Porém, esta realidade terminou no mundo que emergiu nos anos 1970. A crise do petróleo desencadeou a retração do Estado e o alargamento das relações de mercado, causando a transformação das economias e mercados de trabalho. O ímpeto era ultrapassar os efeitos da recessão para melhor corresponder à crescente competitividade internacional. Como resposta ao elevado desemprego, a flexibilidade contratual passou a ser solução, dando origem a uma periferia de emprego precário sem proteção laboral nem união sindical. Assistiu-se, assim, a uma mudança no papel do Estado, tanto na economia como nas relações laborais, da qual viria a consolidar-se a ideologia neoliberal enquanto orientação política, económica e social. Os anos 1990 e 2000 seguiram as tendências neoliberais no mercado de trabalho, e com o "esvaziamento do estado social", o workfare desenvolveu-se. A habilidade das empresas em competir num mercado global assentou na "ativação dos desempregados" através da formação, da eficiência na colocação e no desenvolvimento das suas capacidades. O emprego precário perpetuou-se pelos sucessivos contratos a termo, fazendo com que o trabalhador 
pudesse estar excluído de qualquer proteção laboral, assistindo-se, ao mesmo tempo, à "restauração" do consentimento individual como mecanismo de sobreposição ao poder dos sindicatos (Hepple \& Veneziani, 2009, pp. 31-128).

Portanto, em 2008, aquando da crise financeira que simbolizou o colapso do sistema financeiro mundial e deu origem a uma crise generalizada, é notório o retorno aos lugares comuns das reformas sociais e laborais dos períodos anteriores, expressas nas recomendações do Fundo Monetário Internacional (FMI), do Banco Mundial, e nas orientações de resposta à crise plasmadas na revisão da Estratégia de Lisboa com a Europe 2020 strategy. A redução dos custos salariais, a contenção na despesa pública com a proteção social e a insistência na adaptabilidade como fator de competitividade, evidenciam que no domínio social os direitos laborais e os mecanismos de proteção continuam a ser perspetivados na lógica herdada do período pré-crise.

O período pós 2008 é marcado pela recuperação dos défices financeiros dos países em crise, nomeadamente, da Irlanda, seguida da Grécia e depois Portugal, os mesmos que pedem ajuda financeira ao FMI e de onde vem a resultar o conceito estruturador do novo cenário político e económico, a austeridade. Na Europa foram implementadas medidas de austeridade com o objetivo de reduzir as despesas do estado, bem como restringir ao máximo os custos relacionados com o trabalho. As recomendações dos diferentes atores internacionais, designadamente, instituições como o FMI e a Organização para a Cooperação e Desenvolvimento Económico (OCDE), recaíram sobre a contínua flexibilização do mercado laboral, juntamente com a descentralização da negociação coletiva (OECD, 2012; Serrano, Xhafa \& Fichter, 2011, p. xxiii). Uma vez mais, na Europa o caminho seguido assentou sobre o signo da flexibilidade e da redução dos custos laborais, evidenciando o caráter instrumental do trabalho face às reformas estruturais (Santos, 2015).

As consequências da austeridade foram nefastas para o mundo do trabalho, ecoando, ainda, no período pós-austeridade. O caso português é disso exemplo, que tomou como guião político, o Memorando de Entendimento sobre as Condicionalidades de Política Económica (2011-2014) assinado em maio de 2011, pela troika (FMI, Banco Central Europeu e Comissão Europeia) e o governo. A austeridade económica abriu caminho para uma intervenção política e social que resultou num corte com os pressupostos de uma "política normal" reconfigurando "estrategicamente os ideais da liberdade, da igualdade e da justiça social, bem como os mecanismos redistributivos e quadros institucionais e legais orientados para a solidariedade e coesão social" (Ferreira, 2014, p. 113).

A Lei n. ${ }^{\circ}$ 23/2012, de 25 de junho, operou, assim, a atualização do Código do Trabalho, representando um conjunto de marcantes mudanças na legislação laboral. 


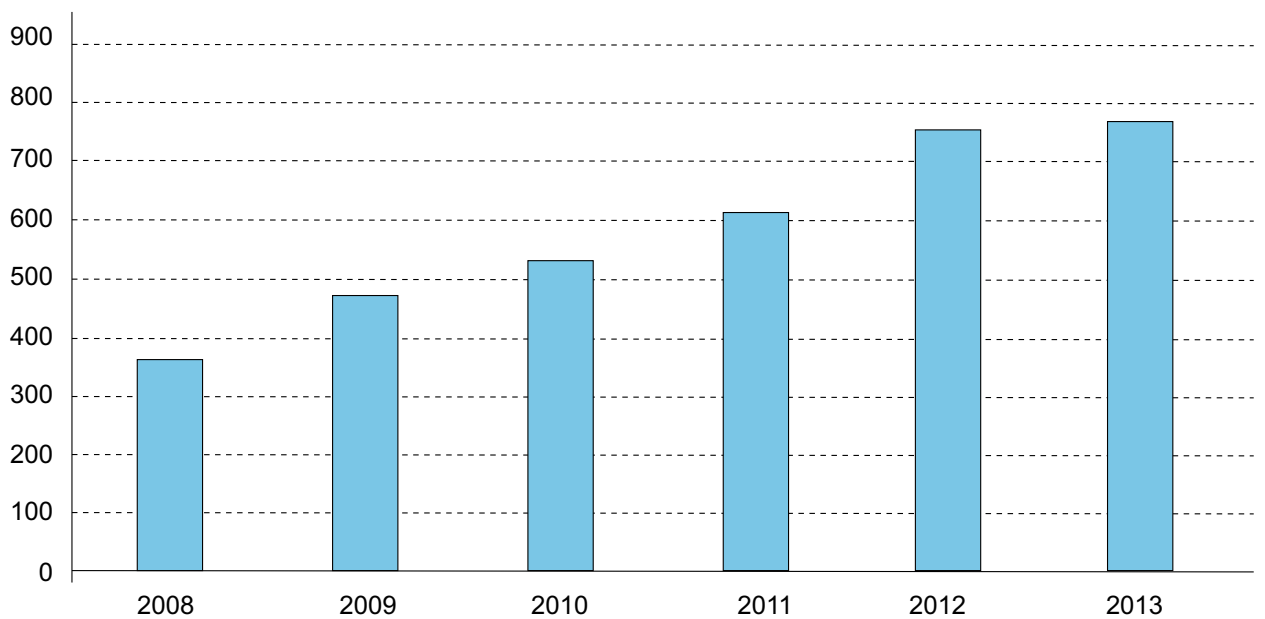

Figura 1 População desempregada total anual, 2008-2013 (n. ${ }^{\circ}$ em milhares)

Fonte: INE.

As medidas focaram o alargamento dos critérios de despedimento, o aumento do tempo de trabalho pela apropriação das férias, feriados, etc., aumento do poder de decisão dos empregadores através do banco de horas acordo individual, facilitação da suspensão e redução de atividade pela situação de crise empresarial, etc., e a contratação coletiva sofreu uma enorme desvalorização. Nos anos que se seguiram à implementação destas medidas, o número de desempregados registou um aumento de 37,7\% entre 2011 e 2013, e como assinala Almeida (2017, p. 1), assistiu-se a uma destruição de 400 mil postos de trabalho no mesmo período.

Neste sentido, não é surpresa que mesmo no cenário pós-austeridade, na esfera laboral, embora a semântica da austeridade comece a desaparecer, a precariedade persista. A este propósito, o Observatório sobre Crises e Alternativas (2018, p. 2) assinalou como tendências da retoma económica: a redução do peso dos contratos permanentes na estrutura do emprego por conta de outrem no setor privado; o predomínio de diferentes tipos de contrato precários; a proliferação do emprego nos serviços; e a degradação das remunerações do trabalho.

A austeridade veio, assim, acirrar as tendências negativas da contínua flexibilidade e precariedade laboral já presentes no mercado de trabalho português. Sob o reconhecimento de uma crise financeira, mas não um questionamento mais profundo que conduziria a uma crise ideológica, o neoliberalismo serviu de suporte à austeridade, através do modo como o económico se sobrepôs às questões políticas e sociais no decurso das últimas décadas (Massey, 2012, p. 100). Apesar do clima 
social "pós austeridade" ser mais positivo, observando-se uma recuperação da atividade económica e uma melhoria global dos indicadores de pobreza e desigualdades, as fragilidades que caracterizavam a economia portuguesa e o perfil do emprego até 2008 não desapareceram a seguir à crise, emergindo, uma vez mais, na sequência da atual pandemia.

Assim, tomando todos de surpresa, a pandemia do Covid-194 que obrigou ao confinamento como forma de travar a propagação do vírus, teve consequências nefastas sob o normal funcionamento das sociedades, tendo um enorme impacto sobre a vida social e económica. É importante realçar que a rápida expansão do vírus não está exclusivamente associada às características e à sua elevada transmissibilidade. A este propósito, Caldas, Silva e Cantante (2020, p. 8) referem que

a velocidade e os padrões da sua disseminação evidenciam a relevância de fatores sociológicos e geoeconómicos, como os fluxos migratórios e turísticos, a divisão internacional do trabalho e da produção, a estrutura de interdependências comerciais globais (...) [ao que acrescem] os incrementos da acessibilidade e da mobilidade às escalas nacional e internacional.

Num mundo globalizado económico e financeiramente, uma crise como a pandemia COVID-19 não só origina emergências de saúde, mas também choques económicos com impacto direto nos mercados, na oferta (produção de bens e serviços), na procura (consumo e investimento) e no mundo do trabalho (OIT, 2020). Em abril de 2020, a Organização Internacional do Trabalho (OIT) assinalava que as medidas de confinamento, parcial ou total, estariam a afetar cerca de 2,7 biliões de trabalhadores, representando $81 \%$ da força de trabalho de todo o mundo (ILO, 2020, p. 1). A contração do emprego foi visível, por exemplo, na redução das horas de trabalho, resultado dos layoffs (suspensão temporária da atividade) e outras formas de redução temporária de horários, sendo possível estimar a diminuição das horas de trabalho em cerca de $6,7 \%$ no segundo trimestre de 2020, o que equivale a 195 milhões de trabalhadores a tempo inteiro.

Entre os setores mais afetados identificam-se o comércio a retalho, a hotelaria e a restauração, e a manufaturação. A atividade económica nestes setores tem sido drasticamente reduzida, representando um corte significativo em termos de receitas. Com o aumento de encerramentos parciais ou totais que restringem as atividades de trabalho e a mobilidade de grande parte dos trabalhadores, para muitos tornou-se impossível trabalhar, enquanto para outros os seus métodos de trabalho sofreram grandes alterações. Estes setores empregam milhões de trabalhadores que são muitas vezes mal pagos, pouco qualificados, o que piora, ainda mais, a sua situação. Empregando à volta de 1,25 biliões de trabalhadores em todo o modo, 
estes setores de atividade representam cerca de $38 \%$ da força de trabalho mundial, e embora nem todos os trabalhadores sejam afetados de forma igual, o que fica patente é que muitos dos trabalhadores afetados têm já salários baixos e pouca, ou quase nenhuma, proteção social. Tal significa que o impacto negativo apenas vem acentuar uma desigualdade já existente. O que nos conduz à economia informal, na qual os trabalhadores não são cobertos pela proteção social associada ao emprego formal, acrescendo, agora, a falta de acesso aos serviços de saúde, como também do subsídio de desemprego caso não possam trabalhar por motivo de doença (ILO, 2020, pp. 1, 5-6).

Relativamente a Portugal, no cenário de pandemia, o governo declarou o estado de emergência, o que ditou o encerramento temporário de várias empresas e restrições à livre circulação de pessoas. O layoff 5 e o teletrabalho passaram a ser alternativas face ao cenário de confinamento, e um grande número de trabalhadores viu as suas vidas alteradas. Segundo os dados do Ministério do Trabalho, Solidariedade e Segurança Social, entre o final de março e o dia 21 de maio, cerca de 111 mil empresas recorreram ao regime de layoff simplificado, abrangendo 1325635 trabalhadores, o que representa 29\% das empresas com trabalhadores ao serviço (Silva, Carmo, Cantante, Cruz, Estêvão, Manso, Pereira \& Lamelas, 2020, p. 2). O layoff, por sua vez, apresenta, também, lacunas quanto à proteção dos trabalhadores abrangidos por este regime. Como assinalam Caleiras e Carmo (2020, p. 5), proíbe-se apenas o recurso ao despedimento coletivo ou por extinção de posto de trabalho e presume-se também o despedimento por inadaptação, acresce que a proibição de despedimento surge limitada no tempo (durante o período de aplicação das medidas de apoio previstas no diploma e nos 60 dias seguintes), pelo que posteriormente nada parece impedir a extinção da relação laboral.

De acordo com os dados do INE (2020, p. 3-4) relativos ao segundo trimestre de 2020, a população empregada (4 731,2 mil pessoas) diminuiu 2,8\% (134,7 mil) em relação ao trimestre anterior, dos quais 116,0 mil trabalhavam por conta de outrem, independentemente do tipo de contrato, mas sobretudo com contrato com termo $(64,1 \mathrm{mil} ; 10,0 \%)$, e também os que trabalhavam por conta própria $(17,7 \mathrm{mil} ; 2,2 \%)$; empregados a tempo completo $(105,7 \mathrm{mil} ; 2,4 \%)$ ou a tempo parcial (29,0 mil; 6,0\%).

Tal demonstra o agudizar da precariedade laboral já existente, contribuindo para um aumento de situações de vulnerabilidade abrangente a um grande número de trabalhadores. Desde o início da pandemia em Portugal até meados de agosto, a legislação laboral foi alterada a cada dois dias, tendo sido publicados 88 documentos legais, desde diplomas que visam especificamente regras laborais ou medidas fiscais que afetam empresas e trabalhadores ${ }^{6}$ (Ferreira e Crisóstomo, 


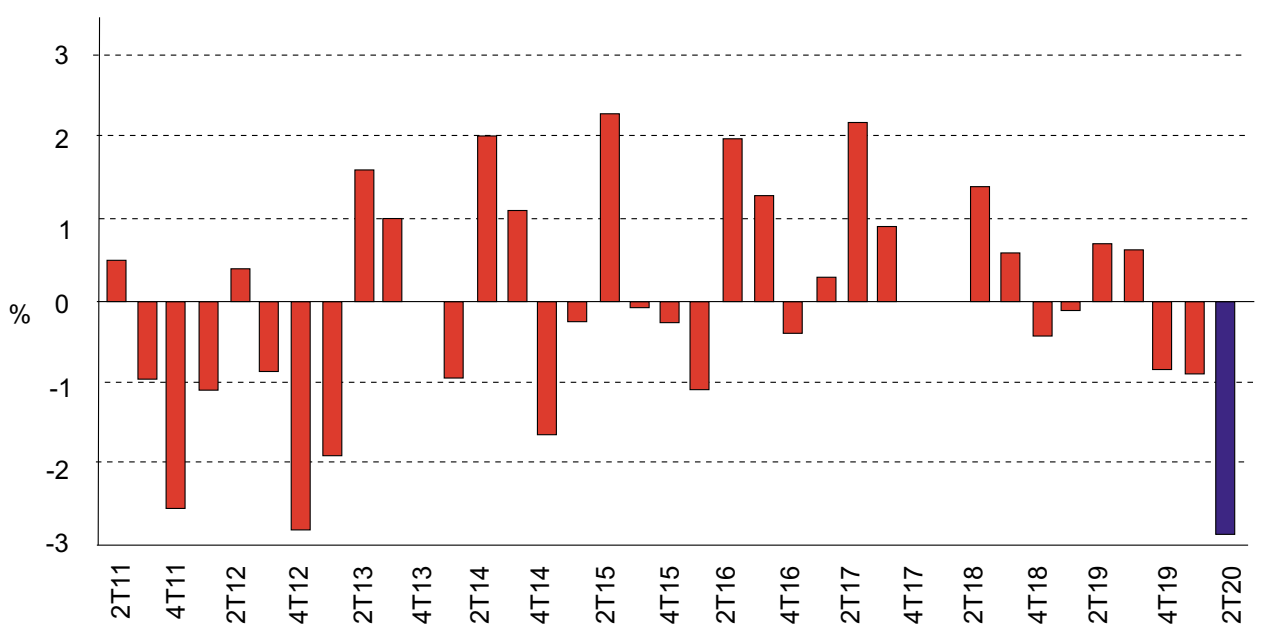

Figura 2 Taxa de Variação trimestral da população empregada Fonte: INE (2020, p. 3).

2020a, p. 18-19). Esta frenética de sucessivas alterações demonstra bem como o trabalho desempenha um papel central na governação política, económica e social.

\section{Velhas e novas questões laborais: uma análise transversal}

Como exposto no tópico anterior, desde a década de 1970 que as crises económicas, naturalmente, se repercutem pelo mundo laboral devido à centralidade do trabalho enquanto pilar fundamental de integração e cidadania social. O trabalho e os seus direitos são colocados como primeiro recurso de resposta, pelo que se torna possível identificar questões que persistem no mundo laboral, como também, novas questões que surgem da necessidade da adaptação a novos contextos.

Quanto às velhas questões, são três as que aqui se destacam. A primeira prende-se com o retorno aos lugares-comuns pelas instituições internacionais face à regulamentação dos mercados de trabalho e suas respostas à crise. Com a expansão do neoliberalismo e do ímpeto da flexibilidade laboral que vem guiando (e desvirtuando) o caráter protetor do direito do trabalho, as respostas à(s) crise(s) representam continuamente a "transposição de um receituário de uso universal desenvolvido por instituições internacionais, como a OCDE, o FMI e a União Europeia (UE), ao longo da década de 1990, muito antes das primeiras manifestações da Grande Recessão" (Silva, Hespanha, Teles \& Caldas 2017, p. 17). A agenda destas 
instituições tem seguido um padrão - contenção na despesa pública com a proteção social e a redução dos custos salariais. Com o argumento da "crise", as políticas de emprego nos diferentes países da UE, até então competência de cada Estado-membro, passaram a ser cada vez mais

uma prerrogativa das instituições da União, à margem do que está instituído nos tratados (...) o programa de flexibilização do mercado de trabalho, promovido pela Comissão Europeia e pelo Banco Central Europeu, é parte do que se assume ser uma condição para a sobrevivência da moeda única, já que o trabalho e o seu custo são tidos como as principais variáveis de ajustamento económico no espaço da zona euro" (Silva, Hespanha, Teles \& Caldas, 2017 p. 28)

Numa análise das políticas de emprego desde a década 1990, passando pelas influências da OCDE e da UE, Teles (2017, pp. 71-72) conclui que o trabalho se tornou na principal variável de ajustamento da economia portuguesa, enquadrada por uma alteração estrutural que afetou os governos nas últimas décadas: "a separação entre a política económica (orçamental, monetária, comercial, industrial, etc.), guiada pelos imperativos da integração europeia, e a política de emprego, agora enquadrada exclusivamente no domínio da política social". O resultado foi que os países da periferia europeia, onde se inclui Portugal, sujeitos às condicionalidades dos credores oficiais se tornaram vítimas da "desvalorização interna", teoria que procura replicar os efeitos de uma desvalorização cambial através da desvalorização salarial (Teles, 2017, pp. 71- 72).

No rescaldo da crise pandémica, a UE tem sido alvo de críticas pelo seu foco essencialmente financeiro que apenas acirra a dívida dos países. Castro Caldas, a este propósito, assinala que o "problema principal é que a única coisa que a União Europeia tem para oferecer (...) é mais crédito, seja qual for a forma desse crédito. Eisso não é o que países que, já de si, estão muito endividados precisam" (citado em Branco, 2020). Na sua perspetiva, os países "precisavam de uma intervenção dos bancos centrais que permitisse basicamente resolver o problema de liquidez que as pessoas e as empresas estão a enfrentar". Acrescenta que a solução passaria pelo estímulo monetário diretamente financiado pelos bancos centrais, que interviriam nos mercados da dívida pública, o que é proibido pelos tratados (citado em Branco, 2020).

Sob este cenário, duas outras velhas questões perduram, as quais se encontram relacionadas entre si: o círculo da precaridade repete-se continuamente, ou seja, os que se encontram numa situação precária, veem a sua condição piorar; e esta mesma precariedade é influenciada e agravada pelos quadros legais, realçando o modo como as práticas sociais dos empregadores estão em dissonância com os princípios jurídicos do direito do trabalho ${ }^{7}$. 


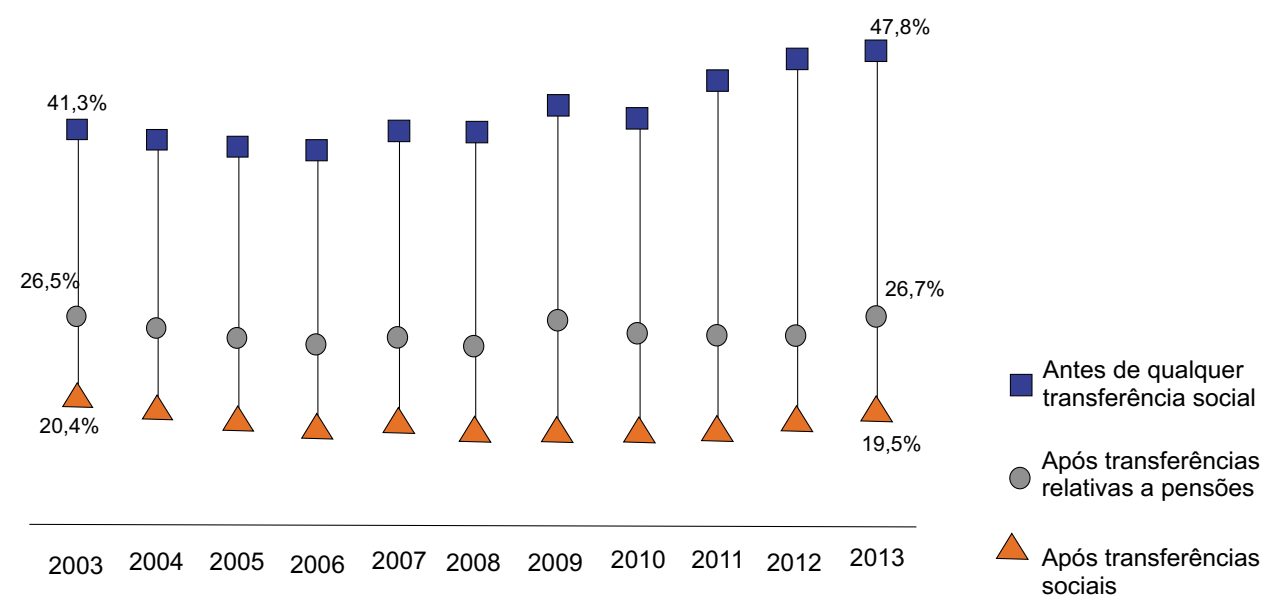

Figura 3 Taxa de risco de pobreza antes e após transferências sociais Fonte: INE $(2015$, p. 3)

Quanto à questão do círculo da precariedade, e tomando como cenário as crises mais recentes, dois exemplos são ilustrativos. Se nos detivermos na crise financeira de 2008 e consequentes medidas de austeridade, em Portugal, 47,8\% da população estava em risco de pobreza considerando os rendimentos associados ao trabalho, de capital e transferências privadas (INE, 2015, p. 3).

Deste modo, e segundo um estudo sobre as consequências sociais do programa de ajustamento,

o efeito conjunto da crise económica, em particular o forte aumento do desemprego, e das alterações introduzidas na legislação laboral traduziram-se numa quebra real do ganho médio equivalente de 6,3\% em termos brutos e de $12,1 \%$ em termos líquidos. Foi igualmente possível comprovar que essa diminuição dos rendimentos do trabalho não afetou de igual forma todos os trabalhadores por conta de outrem e que foi entre os trabalhadores de menores salários que a quebra dos rendimentos mais se fez sentir. (Rodrigues, 2016, p. 101)

A diferença de rendimento entre trabalhadores por conta de outrem com diferentes tipo de vínculo contratual foi também notória, dado que os trabalhadores com contrato permanente auferiram cerca de $50 \%$ mais do que os trabalhadores com contrato temporário, em 2014, assinalando que foi sobre os trabalhadores com vínculos mais precários que as consequências sociais da crise foram também mais sentidas (Rodrigues, 2016, p. 106). Deste modo, diferentes fatores, como o aumento do 
desemprego, cortes no salário e aumento da carga fiscal, vieram piorar situações de pobreza já existentes (Rodrigues, 2016, p. 148).

No mesmo sentido, também na recente crise pandémica, e como anteriormente referido, os trabalhadores com contratos a prazo ou vínculos ainda mais frágeis, foram os que mais perderam o emprego nos últimos meses, a que acresce um nível de escolaridade mais baixo e predominantemente a trabalhar nos serviços (Aníbal, 2020, p. 2; INE, 2020). A pandemia teve como efeito direto o

crescimento das desigualdades sociais devido ao aumento do desemprego nas suas múltiplas formas, em especial, dos trabalhadores precários "dependentes" ou "independentes" (em período experimental, a termo, em trabalho temporário, a recibos verdes, de plataformas eletrónicas, autónomos e intermitentes das artes, etc.) da economia formal e da informal (trabalho doméstico, turismo, restauração, biscates das reparações, etc.) (Pedroso, 2020).

A situação de precariedade é agudizada pelo facto de a grande maioria dos referidos trabalhadores não ter acesso ao subsídio de desemprego por não ter um vínculo laboral formal ou por não ter o número de dias de contribuições suficientes para cumprirem o período de garantia do regime de segurança social, como, ainda, nenhum direito a qualquer outra prestação social dos regimes de proteção social, excetuando os eventuais apoios da ação social pública ou de entidades do terceiro setor (Pedroso, 2020).

Assim, ligada a esta questão encontra-se a forma como a legislação laboral é crescentemente desvirtuada do seu sentido protetor da parte mais fraca, e ainda, como é contornada, fazendo-se uso de uma interpretação deslaboralizada dos seus princípios. Tomando novamente como exemplo as recentes crises, com as alterações à legislação laboral em Portugal resultantes do Memorando é importante reter que

a redução para metade da retribuição por trabalho suplementar e por trabalho em feriado resultou num corte médio da retribuição total do trabalhador em 2,3\% em 2013 (...) Com o fim do descanso compensatório, o tempo de produção suplementar aumentou na prática $33 \%$. Ao mesmo tempo, a retribuição pela totalidade do trabalho suplementar reduziu-se a metade (...) Ao eliminar 4 feriados, 3 dias de férias e acabando com o descanso compensatório pelo trabalho suplementar, as alterações provocaram em termos médios um corte de $20,8 \%$ do tempo de descanso dos trabalhadores (...) Ao fim de um ano, o trabalhador em análise deu à empresa mais 7,9 dias úteis de trabalho (...) Este conjunto de alterações redundou num conjunto de vantagem concedidas às empresas que (...) poderá oscilar entre os 2,1 e 2,5 mil milhões de euros (Leite, Costa, Silva \& Almeida, 2014, p. 184-185). 
A negociação coletiva foi, também, alvo de destaque. A diminuição da cobertura das convenções coletivas e os limites introduzidos pelo código de trabalho à negociação coletiva em diversas matérias fundamentais na regulação das relações laborais, evidenciaram um maior aprofundamento face às medidas enunciadas no Memorando (Lima, 2015). Neste cenário, foi notória a perda de autonomia dos parceiros sociais, enfraquecendo, principalmente, o poder dos sindicatos (Leite, Costa, Silva \& Almeida 2014).

Mais recentemente, no cenário de pandemia e com a introdução do estado de emergência que resultou na "suspensão do mundo laboral"8, verificou-se "um conjunto de situações que têm dado azo a interpretações contra legem, bem como medidas incongruentes com os objetivos a que se propõem" (Lamelas \& Silva, p. 2). Várias denúncias chegaram aos sindicatos de empresas que como forma de responder à crise vão contornando a lei laboral, seja através de despedimentos de trabalhadores precários, imposição unilateral de gozo de férias e recusas de teletrabalho, ou desrespeito pelas normas de proteção (Lopes, 2020). A título ilustrativo, com o encerramento dos estabelecimentos, nomeadamente de retalho, começaram a ser impostas férias aos trabalhadores, em que o próprio pagamento de subsídio de férias seria suspenso durante esse período, prometendo a sua retribuição para mais tarde. Tal prática, e não se tratando de microempresas, é considerada abusiva pelos especialistas em direito do trabalho (Ferreira \& Crisóstomo, 2020b). Para além disso, também o teletrabalho tem sido alvo de polémica devido ao recurso a programas ocultos de vigilância remota de trabalhadores, os quais permitem controlar as suas ações online e a informação que partilham e a que acedem. Sindicatos, advogados e até a própria Comissão Nacional de Proteção de Dados dizem que a prática, ainda que ilegal e punida por lei, está a ganhar terreno e aumentou exponencialmente com a massificação do teletrabalho (Mateus, 2020).

O mundo laboral tem estado, portanto, sob uma constante pressão, pelo que a estas velhas questões, se juntam outras que merecem consideração dada a sua pertinência nos tempos atuais. Três novas questões são aqui realçadas.

A primeira assenta, precisamente, sobre a questão do teletrabalho. Esta nova modalidade laboral constitui-se num bom exemplo da forma como o mundo do trabalho se adaptou às novas circunstâncias e como isso tem impacto sobre o prisma do que é o espaço de trabalho, os recursos disponíveis e os tempos laborais, realçando a complexidade das suas diferentes dimensões. Num estudo recente sobre a adaptação ao teletrabalho (Silva et al., 2020, p. 1), assinala-se que esta tem sido mais fácil em alguns setores e para trabalhadores com perfis de qualificação mais elevados, evidenciando que esta alteração do quotidiano tem profundas implicações para as sociabilidades e para a relação com o tempo e com o espaço. De acordo com o estudo, a adaptação ao teletrabalho passou, por um lado, por uma aprendizagem no uso das diversas plataformas existentes e, por outro, pela tentativa (mais ou menos 
conseguida) de organizar o tempo e o espaço de forma diferente do habitual, onde as condições socioeconómicas, de habitação, assim como as composições dos agregados familiares tiveram um papel fundamental (Silva et al., 2020, p. 19). Tal demonstra, também, o impacto das novas tecnologias no regime do teletrabalho, expondo cada vez mais o processo de trabalho das empresas à digitalização, e como a esfera laboral tem uma ténue fronteira com a esfera privada e familiar.

Agregando os resultados numa análise de ordem espacial, relacional e temporal, os autores identificaram os seus aspetos mais negativos. Quanto ao espaço, deve-se essencialmente à experiência física do próprio confinamento, isto é, "um crescente cansaço e mal-estar físico associado à quarentena, resultante de se passar muito tempo nas mesmas posições físicas, sentado à secretária ou parado em frente ao computador" (Silva et al., 2020, p. 20). Para além disso, acrescem distúrbios de ordem mental, de sintomas depressivos e de desânimo, e de stress devido à conjugação de múltiplas atividades que se cruzam no espaço doméstico. No que diz respeito à dimensão relacional, experiencia-se a deterioração das relações sociais e afetivas entre os elementos do agregado familiar, principalmente, nas famílias com filhos a cargo. O processo de autonomia na gestão do tempo, central à conciliação da vida profissional e familiar, torna o quotidiano muito exigente, repercutindo-se no ambiente emocional. Relativamente às relações de trabalho, assinala-se a "necessidade e a importância das interações presenciais com os colegas e das dinâmicas decorrentes do trabalho em equipa, cuja riqueza se perde nas reuniões virtuais utilizando as diferentes plataformas digitais" (Silva et al., 2020 p. 22). Quanto à dimensão temporal, surge a ideia de um tempo sem fim, em que basicamente se está sempre a trabalhar ou não se cessa de trabalhar por períodos que se prolongam, com a "perceção e a sensação de uma temporalidade adversa e desgastante sobre a qual se tem pouco ou nenhum controlo (...) não havendo fronteiras estabelecidas entre o tempo de trabalho e, por exemplo, as pausas para almoço ou jantar" (Silva et al., 2020, p. 22).

Também outro estudo sobre Teletrabalho e Saúde Ocupacional conclui que existe falta de apoio por parte das empresas, quer ao nível da saúde e segurança do trabalho, quer ao nível de comparticipação de equipamentos e meios de trabalho, alertando que as "relações de trabalho na modalidade teletrabalho colocam grandes desafios que não se esgotam em dimensões, por exemplo, organizacionais ou jurídicas (...)" $)^{\prime \prime}$. Da mesma forma, o atual regime jurídico do teletrabalho, previsto no Código do Trabalho, carece de ser revisto por prejuízo de estar desadequado aos tempos atuais (Lamelas \& Silva, 2020, p.18). Acresce que grande parte dos Instrumentos de Regulação Coletiva de Trabalho não contém qualquer menção ao teletrabalho (remetendo para o código do Trabalho), o que pode abrir as portas à discricionariedade patronal (Fonseca, 2020). 
Partindo desta última questão, o teletrabalho constitui igualmente um desafio que vem desvelar uma outra questão, que embora recorrente, se apresenta agora com novas nuances: a importância e redescoberta do coletivo, nomeadamente, dos sindicatos. Como refere Hermes Costa,

O teletrabalho ganhou uma acuidade que não estava propriamente na agenda dos sindicatos. Com esse regime, os ecos de um enfraquecimento da dimensão coletiva do trabalho são o corolário do afastamento do tradicional local de trabalho. Desse modo, o espírito de mobilização sindical fica confinado a um ativismo digital ainda muito embrionário (citado em Carvalho \& Oliveira, 2020)

A digitalização da economia e do trabalho tem vindo a colocar novos desafios em vários planos, dando origem a mudanças profundas na estrutura do emprego, ainda que de forma diferenciada entre países e regiões e setor de atividade. Os sindicatos enfrentam, assim, um desafio importante que decorre do efeito cruzado da precarização e digitalização. As tecnologias combinadas com novos métodos de gestão digitais estão a transformar a organização do trabalho desafiando identidades profissionais e restringindo as oportunidades de organização coletiva dos trabalhadores. É reconhecido que as novas formas de emprego, onde prolifera a precariedade, são caracterizadas pelo distanciamento dos trabalhadores em relação aos sindicatos. Na grande maioria dos casos, e embora tal necessidade seja amplamente reconhecida, as estratégias colocadas em prática pelo movimento sindical nem sempre são eficazes ou mesmo consistentes (Estanque, Costa, Fonseca \& Santos, 2018, p. 595-598). Esta nova crise veio, portanto,

desafiar os sindicatos a compromissos mais sólidos não só 'internos' (dentro dos sindicatos e entre sindicatos com distintas orientações ideológicas), mas sobretudo 'externos', pois são os setores mais vulneráveis da força de trabalho (trabalhadores temporários, em outsourcing, a recibo verde, com contratos a prazo, em período experimental) os primeiros afetados pela atual pandemia (citado em Carvalho \& Oliveira, 2020).

Esta questão realça a importância da dimensão coletiva, bem como o reforço de alianças entre o tradicional e o alternativo. As soluções podem assentar numa pressão conjunta de denúncia e resistência perante situações de desemprego e precarização, numa combinação entre o sentido tático das lutas sindicais e a virtuosidade do ativismo digital típico das associações de precários, pressionando os sindicatos a mobilizarem os seus associados no apoio a campanhas "à distância", usando recursos e estratégias de comunicação digital, ainda que de modo complementar (Costa, 2020).

As novas formas de adaptação laboral a esta realidade pandémica incitam a alianças profícuas - já anteriormente visíveis no cenário de austeridade (Fonseca, 
2016) - que garantam a proteção dos direitos laborais e reforcem a identidade coletiva dos trabalhadores. O que nos conduz a uma terceira nova questão, o próprio conceito de trabalhador. O trabalhador "atípico" (com diferentes vínculos precários) tem vindo a tornar-se cada vez mais "típico" em vários países europeus (Gumbrell-McCormick, 2011). A precariedade laboral tem sido o denominador comum perante as transformações políticas, económicas e sociais dos últimos tempos, e a crise pandémica ao surgir sob os efeitos a longo prazo da anterior crise financeira, veio expor a situação precária de milhões de trabalhadores que agora se encontram sem qualquer proteção social. O cenário atual veio dar maior visibilidade àqueles que se encontram fora do emprego convencional - os trabalhadores temporários, em período experimental, com contratos a prazo, a recibo verde, entre outros. Neste sentido, a necessidade de um conceito mais alargado de trabalhador que possa fornecer a mesma igualdade a todos, constitui-se num debate urgente.

Uma nova definição deve incluir não somente o trabalhador tradicional, mas alargar o seu escopo de proteção laboral e segurança social a todos os trabalhadores cujo único rendimento provém do seu trabalho individual. A resposta a esta crise, no entender de vários autores, passa por uma maior coesão social e solidariedade na esfera laboral, assente na ideia de "relação de trabalho individual", orientada por uma normatividade fundada na dignidade, capacidade e estabilidade, e na máxima de que o "trabalho não é uma mercadoria" (Freedland \& Countoris, 2011; Countoris, Stefano, Ewing \& Freedland, 2020). O que nos remete, igualmente, para os objetivos do próprio direito do trabalho. O incentivo para que seja minimizada a mercadorização do trabalho está diretamente relacionado com a proteção da dignidade dos trabalhadores (Davidov, 2016, p. 61). Proteger a dignidade humana era um dos principais objetivos do direito do trabalho articulado por Hugo Sinzheimer, considerado por muitos como um dos grandes fundadores do direito do trabalho. Assim, retomando a essência do direito do trabalho, é também possível alargar o seu âmbito de forma a contemplar todos os trabalhadores. Uma solução é melhorar as articulações tradicionais do direito do trabalho, adicionando também justificações universais a par com as justificações seletivas - complementando-as e não as substituindo (Davidov, 2016, p. 71).

Recuperando o pensamento de Sinzheimer, ao revisitar a sua conceção tradicional de direito do trabalho, a autora Ruth Dukes (2011) é instigante a este respeito. A partir da ideia de criar uma constituição económica ou laboral do autor, há um núcleo do seu pensamento que pode ser generalizado: o reconhecimento da humanidade do trabalhador. Ao estabelecer este princípio, afirma-se o respeito pela dignidade e pela liberdade humanas no contexto das relações laborais, cujo papel é indispensável na construção de sociedades livres e igualitárias (Dukes, 2011, p. 57). Esta 
perspetiva assinala a importância de considerar a contribuição do direito do trabalho para a função constitucional de estabelecer uma certa ordem social e económica, destacando o facto da regulação das relações laborais não poderem ser consideradas de forma isolada de um contexto constitucional mais amplo. Contra aqueles que argumentam que o direito do trabalho deve ser adaptado às necessidades do mercado, a ideia da função constitucional do direito do trabalho permite-nos manter um limite crítico - resistir à lógica de mercado onde essa mesma lógica cause danos, mantendo o foco no papel e objetivos do direito do trabalho que tem em consideração a humanidade do trabalhador como referência principal (Dukes, 2011, p. 65-66).

\section{Conclusão}

Face aos argumentos que sustentam a centralidade do trabalho no funcionamento das sociedades, a sua instrumentalização enquanto pedra angular na regulamentação económica, política e social, e as velhas e novas questões que nos permitem identificar continuidades e possibilidades no mundo laboral, apresentam-se três respostas à pergunta sobre qual o valor do trabalho.

A primeira é a de que o trabalho foi, é e será sempre fundamental no funcionamento das sociedades. O seu fim anunciado por entre dinâmicas societais, alterações estruturais e transformações tecnológicas, deixa perceber que o trabalho resiste porque é o laço permanente que liga o indivíduo à sociedade, o cidadão à democracia e a ação à transformação. $\mathrm{O}$ trabalho estabelece com cada indivíduo uma ligação que é tanto individual como coletiva, e a sua riqueza enquanto vínculo assenta nesta mesma complexidade que se estende a todas as esferas do indivíduo, como a todas as áreas da sociedade. Enquanto elemento de integração e inclusão social, e o seu oposto, que reside na vulnerabilidade e na exclusão, o trabalho é o ponto decisivo na construção de sociedades mais justas e democráticas.

O que nos conduz à segunda resposta. O valor do trabalho é, igualmente, o reflexo de escolhas e ideologias políticas, o que requer uma mudança mais profunda nas sociedades. As transformações políticas, económicas e sociais a que se assiste desde a década de 1970, em que os recursos económicos determinam as tomadas de decisão nos processos políticos, deixam perceber que na esfera laboral, a produção do direito traduz opções políticas e ideológicas que seletivamente são impostas através de normas jurídicas (Britto, 2012). As diferentes configurações políticas e correspondentes práticas sociais tornam-se reflexo de como o trabalho e os seus direitos, através dos contornos socioeconómicos, produzem uma justificação normativa nas sociedades. É por isso que, como referido anteriormente, a revisão das leis 
laborais surge, invariavelmente, como primeiro recurso para a resolução de dificuldades económicas e sociais. Se os mercados precisam de funcionar, os direitos dos trabalhadores adaptam-se, e se é preciso mais investimento financeiro, reduzem-se os custos com o trabalho. Entre as demandas dos mercados financeiros e as orientações das instituições internacionais, os governos tomam decisões que colocam em prática através da regulamentação do mundo do trabalho. Assim, quando falamos de justiça social e sociedades mais democráticas, estamos também a falar de direitos e garantias associados ao trabalho. A sociedade funciona como um todo, e a economia não pode assentar somente na produção de números. É preciso reconhecer que a produção e distribuição de riqueza tem como motor o fator humano, e como tal é necessário reconhecer a dignidade humana do trabalhador e estabelecer condições que promovam a coesão e o bem-estar social.

Portanto, a terceira resposta reside nesta última premissa, o valor do trabalho é o valor da pessoa que o desempenha, pelo que valorizando a variável trabalho, está-se a exponenciar o potencial da sociedade como um todo. Ao admitirmos que as decisões tomadas assentam sobre ideais essencialmente financeiros que conduzem sistematicamente a momentos de rutura e persistem num círculo de resgate desses mesmos ideais; ao reconhecermos que a precariedade laboral aumenta continuamente, colocando cada vez mais trabalhadores numa situação de vulnerabilidade e insegurança; e ao observarmos que esta precariedade é influenciada e agravada pelos quadros legais que estão em dissonância com os princípios jurídicos do direito do trabalho está-se a ignorar a dignidade humana e os mecanismos redistributivos e quadros institucionais e legais orientados para a solidariedade e coesão social. Os tempos atuais desafiam a parte "tradicional" da relação laboral, impondo uma reflexão sobre o tempo e o espaço laborais, a importância do coletivo e a própria definição de trabalhador e escopo do direito do trabalho. Afirmar o valor do trabalho passa, portanto, por definir a humanidade do trabalhador como referência principal para a regulamentação das relações laborais, estendendo as garantias e proteção do direito do trabalho a todos os que fornecem a sua força de trabalho. Como? Através da identificação e limitação das situações de precariedade e contornos à lei, e enquadramento de "velhos e novos" elementos e atores no mundo do trabalho. Quanto a este último ponto, enquanto elemento fundamental do trabalho, a sua dimensão coletiva deve ser reforçada por novas alianças que permitam agregar a força de trabalho sobre um ideal comum: tornar a esfera laboral o reflexo de uma sociedade mais justa e democrática para todos. 


\section{Agradecimentos}

Este trabalho tem o apoio financeiro da Fundação para a Ciência e a Tecnologia (FCT/MEC) com verbas do Orçamento do Estado, do Fundo Social Europeu, disponibilizadas ao abrigo do PORTUGAL 2020, através do Programa Operacional Regional do Centro (Centro 2020) no âmbito da Bolsa de Doutoramento SFRH/BD/121020/2016. Agradece-se, ainda, aos revisores do artigo as apreciações e sugestões apresentadas.

\section{Notas}

Por decisão pessoal, a autora escreve segundo o novo acordo ortográfico.

1 Consultar O capital (Marx, 2017 [1867]).

2 Consultar A Divisão do Trabalho Social I (Durkheim, 1977 [1893]).

3 Consultar A Ética Protestante e o Espírito do Capitalismo (Weber, 1967[1905]).

4 Em janeiro de 2020, a Organização Mundial da Saúde declarou o surto de uma nova doença provocada por um coronavírus na província de Hubei, na China, como uma emergência de saúde pública internacional. No dia 11 de março de 2020, declarou o surto de COVID-19 como uma pandemia.

5 Para além do layoff, também ficaram disponíveis "prorrogações automáticas de prazos (do subsídio de desemprego e de outras prestações sociais), flexibilização das obrigações fiscais e perante a Segurança Social, apoios (ainda que minimalistas) a trabalhadores independentes, a famílias, para que os filhos possam ser cuidados em casa ou para que não possam ser já despejadas, linhas de crédito a empresas com poucas condicionalidades" (Caleiras \& Carmo, 2020, pp. 3-4).

6 Acrescem, ainda, decretos presidenciais do estado de emergência, os quais são textos mais genéricos de resposta à evolução da pandemia, mas que também afetam as relações de trabalho (Ferreira \& Crisóstomo, 2020a).

7 Conferir Santos (2012).

8 Não obstante, e ainda que, estruturalmente, não tenha havido uma alteração substantiva do regime legal laboral, a situação conjuntural vai no sentido de assegurar a manutenção dos postos de trabalho. Porém, deve ter-se presente que a declaração do estado de emergência suspendeu o exercício de dois direitos fundamentais: o direito à greve em setores essenciais e, de forma generalizada, o direito de iniciativa privada (Lamelas, 2020, p. 4).

9 Disponível em https://barometro-covid-19.ensp.unl.pt/saude-ocupacional/Resultados/. 


\section{Referências}

Almeida, J. R. (2017). Novo emprego. Que emprego? Barómetro das Crises - Observatório sobre Crises e Alternativas, 16, 1-14.

Aníbal, S. (2020, 6 de agosto). Precários na linha da frente na perda de emprego na pandemia. Jornal Público, pp. 2-3.

Branco, S. (2020) Covid-19: Crise terá forte impacto no mercado laboral. Disponível em: https://www.dinheirovivo.pt/economia/covid-19-crise-tera-forte-impacto-no-merca do-laboral/?fbclid=IwAR1PP4KwXMx9D82BxYFBtJFDfrFotx8b9WoLVY96zG9GhyZe DWvz-BOcCxc

Britto, C. (2012). Aspectos históricos e ideológicos na construção do direito do trabalho. Revista do Tribunal Superior do Trabalho, 78 (1), 44-66.

Caldas, J. C., Silva, A. A., \& Cantante, F. (2020). As consequências socioeconómicas da COVID-19 e a sua desigual distribuição. Lisboa: CoLABOR.

Caleiras, J., \& Carmo, R. M. (2020). O regresso do desemprego massivo? Estudos CoLABOR, 1.

Carvalho, M., \& Oliveira, O. (2020, 1 de maio). Sindicalismo pós-Covid. A carga de trabalhos para quem representa os trabalhadores. Visão. Disponível em https://visao.sapo.pt/atualidade/politica/2020-05-01-sindicalismo-pos-covid-a-carga -de-trabalhos-para-quem-representa-os-trabalhadores/

Costa, E. S., \& Almada, P. (2018). Mundo do trabalho e pluralidade epistemológica: Uma contribuição para o estudo da precariedade. Sociologia: Revista da Faculdade de Letras da Universidade do Porto, XXXV, 161-179.

Costa, H. C. (2020). Sindicalismo. In J. Reis (Coord.), Palavras para lá da pandemia: Cem lados de uma crise (p. 99). Coimbra: Centro de Estudos Sociais, Universidade de Coimbra. Disponível em https://ces.uc.pt/publicacoes/palavras-pandemia/?lang=1\&id=30293

Countouris, N. (2019). Defining and regulating work relations for the future of work. Geneva: ILO.

Countouris, N., Stefano, V., Ewing, K., \& Freedland, M. (2020, 9 de abril). Covid-19 crisis makes clear a new concept of 'worker' is overdue. Social Europe online. Disponível em https:/ / www.socialeurope.eu/covid-19-crisis-makes-clear-a-new-concept-of-worker-is-over due?fbclid=IwAR0cnfkMex1Xdbc_uC3T-Wub7r566JRbDcp3HMv81bi2ezXp44ajSJ0qDa0

Davidov, G. (2016). A purposive approach to labour law. Oxford: Oxford University Press.

Dejours, C., \& Deranty, J. P. (2010). The centrality of work. Critical horizons, 11 (2), 167-180.

Deranty, J. P. (2015). Historical objections to the centrality of work. Constellations, 1(22), 105-121.

Dukes, R. (2011). Hugo Sinzheimer and the constitutional function of labour law. In G. Davidov \& B. Langille (Orgs.), The idea of labour law (pp. 57-68). Oxford: Oxford University Press.

Durkheim, É. (1977 [1893]). A divisão do trabalho social I. Lisboa: Editorial Presença. 
Estanque, E., \& Costa, H. A (2012). Trabalho, precariedade e movimentos sociolaborais. In S. F. Casaca (Org.), Mudanças laborais e relações de género: Novos vetores de (des)igualdade (pp. 165-203). Lisboa: Almedina.

Estanque, E., Costa, H., Fonseca, D., \& Santos, A. (2018). Digitalização e precariedade laboral: Novos desafios para o sindicalismo e os movimentos sociais no contexto português. Século XXI - Revista de Ciências Sociais, 8(2), 589-621.

Fernandes, A. M. (2012). As primeiras estações da reforma laboral: Tempo de trabalho, tempo de não trabalho, compensação de despedimento. Revista de Direito e de Estudos Sociais, 53(1-2), 101-109.

Ferreira, A. C. (2014). Política e Sociedade: Teoria social em tempo de austeridade. Porto, Vida Económica.

Ferreira, V., \& Crisóstomo, P. (2020a, 19 de agosto). Legislação laboral alterada a cada dois dias durante a Pandemia. Jornal Público, 18-19.

Ferreira, V., \& Crisóstomo, P. (2020b, 20 de março). Há empresas a usar férias dos trabalhadores para se salvarem. Jornal Público, 6.

Fonseca, D. (2016). Movimentos sociais e sindicalismo em tempos de crise. O caso português: Alianças ou tensões latentes? (Tese de Doutoramento, FEUC, Coimbra, Portugal).

Fonseca, D. (2020). Teletrabalho. In J. Reis (Coord.), Palavras para lá da pandemia: Cem lados de uma crise (p. 105). Coimbra: Centro de Estudos Sociais, Universidade de Coimbra. Disponível em https://ces.uc.pt/publicacoes/palavras-pandemia/ ?lang=1\&id=30377

Freedland, M., \& Countouris, N. (2011) The Legal Construction of Personal Work Relations. Oxford: University of Oxford

Freyssenet, M. (1999). The emergence, centrality and end of work. Current Sociology, $47(2), 5-20$.

Gumbrell-Mccormick, R. (2011). European trade unions and 'atypical' workers. Industrial Relations Journal, 42(3), 293-310.

Hepple, B., \& Veneziani, B. (Eds.) (2009). The transformation of labour law in Europe. A comparative study of 15 countries 1945-2004. Oxford: Hart Publishing.

ILO, International Labour Organization. (2018). Global Commission on the future of work individuals, work and society. Geneva: International Institute for Labour Studies.

ILO, International Labour Organization. (2020). Managing conflicts and disasters: Exploring collaboration between employers' and workers' organizations. Geneva: ILO.

INE, Instituto Nacional de Estatística. (2015). Rendimento e condições de vida 2014 (Dados definitivos). Lisboa: INE.

INE, Instituto Nacional de Estatística. (2020). Estatísticas do emprego 2. ${ }^{\circ}$ trimestre de 2020. Lisboa: INE.

Lamelas, F. (2020). Proteção do emprego em tempos de COVID-19. POLÍTICAS EM ANÁLISE, (1).

Lamelas, F., \& Silva, A. A. (2020). Insuficiências das medidas excecionais de proteção do emprego no âmbito da covid-19. POLÍTICAS EM ANÁLISE, (3). 
Leite, J., Costa, H., Silva, M. C., \& Almeida, J. R. (2014). Austeridade, reformas laborais e desvalorização do trabalho. In J. Reis (Coord.), A economia politica do retrocesso crise, causas e objetivos (pp. 127-188). Coimbra: Almedina.

Lima, M. da P. C. (2015). A reconfiguração do regime de emprego e de relações laborais em Portugal na ótica liberal. Cadernos do Observatório - Observatório sobre Crises e Alternativas, 5, 1-30.

Lopes, M. (2020, 27 de março). PCP junta denúncia que mostram fugas à lei laboral. Jornal Público, 14-15.

Marx, K. (2017 [1867]). O capital. Lisboa: Edições 70.

Massey, D. (2012). Ideology and economics in the present moment. In J. Rutherford \& S. Davison (Eds.) The neoliberal crisis (pp. 97-107). Londres: Soundings LW.

Mateus, C. (2020, 21 de agosto). Empresas portuguesas espiam funcionários em teletrabalho. Expresso Economia. Disponível em https:/ / expresso.pt/economia/2020-08-21-Empresas-portuguesas-espiam-funcion arios-em-teletrabalho

Méda, D. (1999). O trabalho - Um valor em vias de extinção. Lisboa: Fim de Século Edições.

Méda, D. (2016). The future of work: The meaning and value of work in Europe. ILO Research Paper, 18, 1-35.

Méda, D., \& Vendramin, P. (2017). Reinventing work in Europe: Value, generations and labour. Londres: Palgrave Macmillan.

Observatório sobre Crises e Alternativas. (2018). Retoma económica: O lastro chamado precariedade. Barómetro das Crises - Observatório sobre Crises e Alternativas, 18, $1-10$.

OECD, Organisation for Economic Co-operation and Development. (2012). Economic policy reforms 2012: Going for growth. Paris: OECD Publishing.

OIT, Organização Internacional do Trabalho. (2019). Trabalhar para um futuro melhor Comissão mundial sobre o futuro do trabalho organização internacional do trabalho. Lisboa: OIT.

OIT, Organização Internacional do Trabalho. (2020). Garantir a segurança e saúde no trabalho durante a pandemia. Lisboa: OIT.

Pedroso, J. (2020). Pandemia, precariedade e proteção social. In J. Reis (Coord.), Palavras para lá da pandemia: Cem lados de uma crise (p. 75). Centro de Estudos Sociais, Universidade de Coimbra. Disponível em https://ces.uc.pt/publicacoes/palavras-pandemia/?lang=1\&id=30474

Rifkin, J. (1995). The end of work: The decline of the global labor force and the dawn of the post-market era. Nova Iorque: Putnam Publishing Group.

Rodrigues, C. F. (Coord.) (2016). Desigualdade do rendimento e pobreza em Portugal: As consequências sociais do programa de ajustamento. Lisboa: Fundação Francisco Manuel dos Santos.

Santos, A. (2012). Uma análise sociojurídica da precariedade laboral: O caso dos falsos trabalhadores independentes (Dissertação de mestrado, FEUC, Coimbra, Portugal). 
Santos, A. (2015). Austeridade e ideologia: A instrumentalização do direito do trabalho. In H. Costa \& G. M. Bester (Orgs.), Ensaios de direito e de sociologia partir do Brasil e de Portugal: Movimentos, direitos e instituições (pp. 21-44). Curitiba: Instituto Memória.

Serrano, M., Xhafa, E., \& Fichter, M. (Eds.) (2011). Trade unions and the global crisis: Labour's visions, strategies and responses. Geneva: International Labour Office.

Silva, M. C. (2007). Trabalho e sindicalismo em tempo de globalização - Reflexões e propostas. Mafra: Círculo de Leitores.

Silva, M. C. (2020). Centralidade do trabalho. In J. Reis (Coord.), Palavras para lá da pandemia: Cem lados de uma crise (p. 27). Coimbra: Centro de Estudos Sociais, Universidade de Coimbra. Disponível em https:/ / ces.uc.pt/publicacoes/palavras-pandemia/ ?lang=1\&id=30363.

Silva, M. C., Hespanha, P., Teles, N., \& Caldas, J. C. (2017). Trabalho e políticas de emprego: Passado com lastro, presente conturbado e futuro indeterminado. In M. C. Silva, P. Hespanha \& J. C. Caldas (Orgs.), Trabalho e políticas de emprego. Um retrocesso evitável (pp. 15-33). Coimbra: Actual.

Silva, P. A., Carmo, R. M., Cantante, F., Cruz, C., Estêvão, P., Manso, L., Pereira, T. S., \& Lamelas, F. (2020). Trabalho e desigualdades no Grande Confinamento (II). (Estudos CoLABOR, N. ${ }^{\circ}$ 2/2020). Lisboa: CoLABOR.

Teles, N. (2017). O trabalho como variável de ajustamento: Da teoria à prática. In M. C. Silva, P. Hespanha \& J. C. Caldas (Orgs.), Trabalho e políticas de emprego. Um retrocesso evitável (pp. 35-78). Coimbra: Actual.

Teles, N., \& Caldas, J. C. (2019). Tecnologia e trabalho no século XXI: Uma proposta de abordagem. Cadernos do Observatório, 12, 1-35.

Weber, M. (1967 [1905]). A ética protestante e o espírito do capitalismo. São Paulo: Pioneira.

Data de submissão: 28/08/2020 | Data de aceitação: 17/11/2020

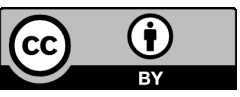

SOCIOLOGIA ON LINE, n. ${ }^{\circ} 25$, abril 2021, pp. 11-34 | DOI: 10.30553/sociologiaonline.2021.25.1 